\title{
Pulse oximetry screening for critical congenital heart disease in term and late pre-term newborn
}

\author{
*Pinar Arican ${ }^{1}$, Sultan Kavuncuoglu ${ }^{2}$ \\ Sri Lanka Journal of Child Health, 2019; 48(4): 308-311
}

\begin{abstract}
Introduction: Neonatal screening for critical congenital heart disease (CCHD) aids in identifying infants for whom early diagnosis and therapy are beneficial.
\end{abstract}

Objective: To study utilisation of pulse oximetry in term and late preterm neonates for early diagnosis of CCHD.

Method: This prospective study was conducted in newborns in the Kanuni Sultan Suleyman Education and Research Hospital, Turkey from December 2012 to August 2013. Pre-ductal and post-ductal pulse oximetry was carried out on all neonates between 24-72 hours of age. Screening was considered to be positive when the oxygen saturation level was $\leq 95 \%$ or if the pre-ductal and post-ductal saturations, taken after 3 hours from the initial measurements, differed by more than $3 \%$.

Results: There were 971 (97\%) babies with negative screening and $29(3 \%)$ babies with positive screening. The sensitivity was $93 \%$, specificity $99 \%$, positive predictive value $81 \%$ and negative predictive value $99 \%$.

Conclusions: Pulse oximetry screening in term and late preterm neonates is effective for early diagnosis of CCHD.

DOI: http://dx.doi.org/10.4038/sljch.v48i4.8823

(Key words: Critical congenital heart disease, early detection, pulse oximetry)

${ }^{1}$ Izmir Tepecik Education and Research Hospital, Turkey, ${ }^{2}$ Kanuni Sultan Suleyman Education and Research Hospital, Turkey

*Correspondence: pinararican@windowslive.com

orcid.org/ 0000-0003-3990-7489

(Received on 14 January 2019: Accepted after revision on 22 February 2019)

The authors declare that there are no conflicts of interest

Personal funding was used for the project.

Open Access Article published under the Creative

Commons Attribution CC-BY CC

\section{Introduction}

Reported prevalence of congenital heart disease (CHD) at birth is 9 per 1000 live births with around $25 \%$ being considered critical ${ }^{1}$. Neonates with such unrecognized critical congenital heart disease (CCHD) can manifest with growth retardation, heart failure, cardiovascular collapse, hypoxicischemic encephalopathy and even death. Early detection has led to a decline in poor postoperative outcome due to $\mathrm{CCHD}^{2,3}$.

Though antenatal ultrasonography usually detects major CHD, they can be missed, especially in developing countries, because of the absence of routine antenatal visits ${ }^{4}$. Pulse oximetry is a noninvasive tool used to detect $\mathrm{CCHD}^{5,6}$. American Academy of Pediatrics recommends pulse oximetry screening of newborns in the case of potential $\mathrm{CHD}^{7}$. Neonatal screening for CCHD aids in identifying infants for whom early diagnosis and therapy are beneficial.

\section{Objective}

To study utilisation of pulse oximetry in term and late preterm neonates for early diagnosis of CCHD.

\section{Method}

This prospective study was conducted on newborns in the Kanuni Sultan Suleyman Education and Research Hospital, Turkey from December 2012 to August 2013. Demographic data was obtained from medical records. The study was approved by the local ethics committee. Written informed consent was received from all parents/ guardians. Patients were included in the study if they were full-term or late preterm newborns. Exclusion criteria included neonates with prenatal diagnosis of CHD and comorbidities such as preterm delivery, respiratory distress syndrome, dysmorphic syndromes, multiple congenital anomalies, and sepsis.

Pre-ductal and post-ductal pulse oximetry was done in all neonates between 24-72 hours of age by placing sensor on right wrist and right foot. Saturations were recorded one minute after a stable reading. Values greater than $95 \%$ were considered normal. Screening was considered to be positive when the oxygen saturation level was $\leq 95 \%$ or if the pre-ductal and post-ductal saturations, taken after 3 hours from the initial measurements, differed by more than $3 \%$. In such instances an echocardiogram was done, without regard to any 
clinical signs. The authors phoned the parents with regard to the status of their child at 3 months after birth if the newborn had negative screening.

CCHD was defined as CHD needing surgery or catheter intervention during infancy, including Dtransposition of great arteries, coarctation of aorta, Fallot's tetralogy, hypoplastic left heart syndrome, pulmonary atresia, hypoplastic or interrupted aortic arch, double outlet right ventricle and truncus arteriosus $^{8}$. The monitoring was conducted using Nellcor Puritan Bennett N-560 pulse oximeters.

Number Cruncher Statistical System 2007 Statistical Software (Utah, USA) was used to calculate frequencies and percentages. Median and interquartile range was used to describe patient age. Chi-square test and Fisher's exact test were used to compare independent groups of categorical data. A $\mathrm{p}$ value $<0.05$ was taken as statistically significant. Sensitivity, specificity, positive and negative predictive values of pulse oximetry screening to detect CCHDs were done.

\section{Results}

One thousand neonates were enrolled in the study of whom 482 (48\%) were females and $518(52 \%)$ were males. The gestational ages ranged from 34 to 40 weeks (mean $37.7 \pm 1.3$ weeks). Birth weights ranged from 1800 to $4850 \mathrm{~g}$ (mean 3224.1 \pm $397.1 \mathrm{~g})$. Six hundred and twenty one (62\%) babies were born by Caesarean section which was the commonest mode of delivery. A comparison of the demographic data between neonates with and without CCHD is shown in Table 1. CCHD was significantly higher in male newborns $(\mathrm{p}<0.05)$.

Table 1: Comparison of demographic data between neonates with and without $\mathrm{CCHD}(\mathrm{n}=1000)$

\begin{tabular}{|l|c|c|c|}
\hline \multirow{2}{*}{ Characteristic } & \multicolumn{2}{|c|}{ Critical congenital heart disease (CCHD) } & \multirow{2}{*}{ p value } \\
\cline { 2 - 3 } & Yes (n=28) & No (n=972) & \multirow{2}{*}{0.035} \\
Sex & $20(71)$ & $498(51)$ & \\
Male n (\%) & $08(29)$ & $474(49)$ & 0.895 \\
\hline Female n (\%) & $20(71)$ & $826(85)$ & \\
34- 37 n (\%) & $08(29)$ & $146(15)$ & 0.083 \\
38-40 n (\%) & $25(89)$ & $860(88)$ & \\
\hline Birth weight (g) & $03(11)$ & $11(12)$ & \\
$\geq 2500 \mathrm{n}(\%)$ & $13(46)$ & $608(63)$ & 0.055 \\
\hline$<2500 \mathrm{n}(\%)$ & $15(54)$ & $364(37)$ & \\
\hline Mode of delivery & & & \\
Caesarean $\mathrm{n}(\%)$ & & & \\
Vaginal n (\%) & & & \\
\hline
\end{tabular}

There were 971 (97\%) babies with negative screening and $29(3 \%)$ babies with positive screening. Of the 971 neonates with negative screening, 6 had oxygen saturation levels $\leq 95$ in the first measurement and showed normal saturation when repeated after 3 hours of initial measurement. Echocardiography was done in all 29 newborns with positive screening. Of the 29 neonates, three had normal cardiac anatomy and function and twenty-six had a pathologic echocardiogram. Of the 971 negative screening patients who had normal oxygen saturation in both measurements, two had a postnatal CCHD diagnosis (Figure 1). 


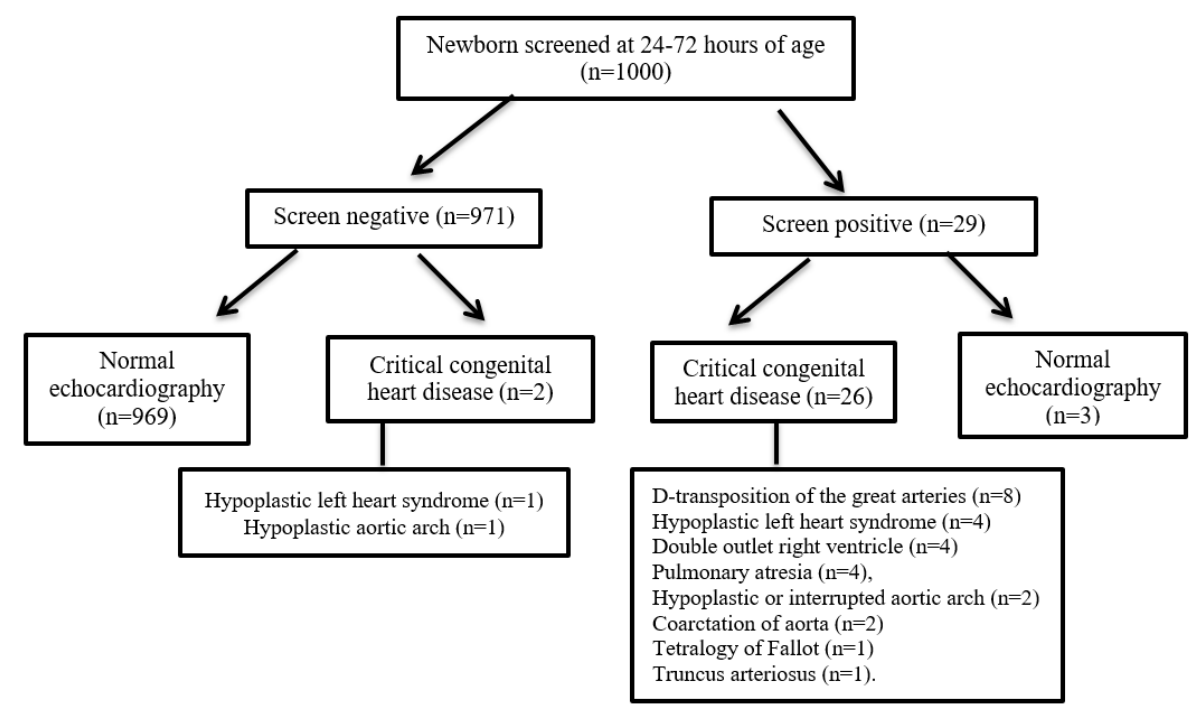

Figure 1: Study flow chart

Pulse oximetry CCHD screening had a sensitivity of $93 \%$, a specificity of $99 \%$, a positive predictive value of $81 \%$ and a negative predictive value of $99 \%$. There was no difference among the predictive performances of pulse oximetry in detecting CCHD between pre-ductal and post-ductal measurements (Table 2).

Table 2: Predictive performance of pulse oximetry in detecting critical congenital heart disease

\begin{tabular}{|l|c|c|c|c|}
\hline Measurement & Sensitivity & Specificity & Positive predictive value & Negative predictive value \\
\hline Pre-ductal & $93 \%$ & $99 \%$ & $81 \%$ & $99 \%$ \\
\hline Post-ductal & $93 \%$ & $99 \%$ & $81 \%$ & $99 \%$ \\
\hline
\end{tabular}

\section{Discussion}

In our study, using pulse oximetry screening we were able to diagnose 26 neonates with CCHD. The prevalence of CCHD in our study was higher than reported prevalence of CHD. This may be due to high-risk pregnancies being referred to our tertiary hospital.

Though early diagnosis and treatment of CCHD is crucial, there is no consensus about the recommended screening protocol for infants with a positive screen $^{9,10}$. In our study, the oxygen saturation threshold was $\leq 95 \%$. We made a second measurement separated by 3 hours from the first measurement if the first neonate saturation was $\leq 95 \%$. Of 971 neonates with negative screening, 6 neonates had oxygen saturation levels $\leq 95$ in first measurement and normal saturation after 3 hours. Therefore two repeated measurements have been shown to be accurate in detecting CCHD.

In our study, sensitivity of pulse oximetry screening was found to be $93 \%$ for detection of CCHD. Several studies have shown that when pulse oximetry is done in the first 24 hours of life, there can be more false positives ${ }^{4,11}$. In our study, pulse oximetry was done between 24-72 hours age. Moreover, newborns with co-morbidities such as preterm delivery, respiratory distress syndrome, dysmorphic syndromes, multiple congenital anomalies and sepsis were excluded from the study. This may account for the lower false positivity rate in our study.

Routine use of pulse oximetry screening may detect CCHD in asymptomatic newborns before hospital discharge. It prevents previously well infants from acute collapse at the time of ductal closure and lead to improve morbidity with worse surgical and neurodevelopmental outcomes.

\section{Conclusions}

Pulse oximetry screening in term and late preterm neonates is effective for early diagnosis of CCHD.

\section{References}

1. Hoffman JI, Kaplan S. The incidence of congenital heart disease. Journal of the American College of Cardiology 2002; 39:1890-900.

https://doi.org/10.1016/S07351097(02)018 86-7

2. González-Andrade F, López-Pulles R. Congenital malformations in Ecuadorian children: urgent need to create a National Registry of Birth Defects. Application of 
Clinical Genetics 2010; 3:29-39.

https://doi.org/10.2147/TACG.S8794

PMid: 23776361

3. Bradshaw EA, Cuzzi S, Kiernan SC, Nagel N, Becker JA, Martin GR. Feasibility of implementing pulse oximetry screening for congenital heart disease in a community hospital. Journal of Perinatology 2012; 32:710.

https://doi.org/10.1038/jp.2011.179

PMid: 22282131 PMCid: PMC3432220

4. Patriciu M, Avasiloaiei A, Moscalu M, Stamatin M. Pulse oximetry during the first 24 hours as a screening tool for congenital heart defects. Journal of Critical Care Medicine 2017; 3:12-7.

https://doi.org/10.1515/jccm-2017-0004

PMid: 29967865 PMCid: PMC5769894

5. de Lira Albuquerque FC, Maia ET, de Figueiredo VL, Mourato FA, da Silva Mattos S. Clinical examination and pulse oximetry to detect congenital heart defects. International Journal of Cardiovascular Science 2015; 28:148-51. https://doi.org/10.5935/23594802.201500 23

6. Ewer AK, Middleton LJ, Furmston AT, Bhoyar A, Daniels JP, Thangaratinam S, et al. Pulse oximetry screening for congenital heart defects in newborn infants (PulseOx): a test accuracy study. Lancet 2011; 378:785-94.

https://doi.org/10.1016/S01406736(11)607 53-8

7. Thangaratinam S, Brown K, Zamora J, Khan KS, Ewer AK. Pulse oximetry screening for critical congenital heart defects in asymptomatic newborn babies: a systematic review and meta-analysis. Lancet 2012; 379:2459-64. https://doi.org/10.1016/S01406736(12)601 07-X
8. Mahle WT, Newburger JW, Matherne GP, Smith FC, Hoke TR, Koppel R et al. Role of pulse oximetry in examining newborns for congenital heart disease: a scientific statement from the AHA and AAP. Pediatrics 2009; 124:823-36. https://doi.org/10.1542/peds.2009-1397 PMid: 19581259

9. Oster ME, Aucott SW, Glidewell J, Hackell J, Kochilas L, Martin GR et al. Lessons learned from newborn screening for critical congenital heart defects. Pediatrics 2016; 137:e20154573. https://doi.org/10.1542/peds.2015-4573 PMid: 27244826 PMCid: PMC5227333

10. Lightfoot M, Hough P, Hudak A, Gordon M, Barker S, Meeder R et al. Audit of pulse oximetry screening for critical congenital heart disease (CCHD) in newborns. Paediatrics and Child Health. 2017; 22:305-6.

https://doi.org/10.1093/pch/pxx091 PMid: 29479241 PMCid: PMC5804783

11. Riede FT, Wörner C, Dähnert I, Möckel A, Kostelka M, Schneider P. Effectiveness of neonatal pulse oximetry screening for detection of critical congenital heart disease in daily clinical routine-results from a prospective multicenter study. European Journal of Pediatrics 2010; 169:975-81. https://doi.org/10.1007/s00431-010-1263$\mathrm{y}$ PMid: 20195633 PMCid: PMC2890074 